\title{
Identification of Brassinolide, Castasterone and Norcastasterone (Brassinone) in Sunflower (Helianthus annuus L.) Pollen
}

\author{
Suguru Takatsuto, ${ }^{\dagger}$ Takao Yokota, ${ }^{*}$ Kumiko OMOte, \\ Keiji GamoH** and Nobutaka TaKahashi* \\ Department of Chemistry, Joetsu University of Education, \\ Joetsu-shi, Nigata 943, Japan. \\ * Department of Agricultural Chemistry, The University of Tokyo, \\ Bunkyo-ku, Tokyo 113, Japan \\ ** Faculty of Education, Kochi University, Akebonocho, \\ Kochi-shi 780, Japan
}

Received March 3, 1989

\begin{abstract}
From the pollen of sunflower (Helianthus annuus L.), the biologically active substances in the rice Iamina inclination test were extracted and partially purified. They were converted to bis-9phenanthreneboronates and bismethaneboronates, and analyzed by fluorescence HPLC and GC/MS analytical methods, respectively. The active principles were identified as brassinolide, castasterone and norcastasterone (brassinone).
\end{abstract}

Pollens have been found to be rich sources of the new plant growth promoter, brassinosteroid. ${ }^{1)}$ Since the discovery of brassinolide from the pollen of rape (Brassica napus L.), ${ }^{2)}$ several pollens have been investigated and demonstrated to contain brassinosteroids: Typha latifolia L., ${ }^{3)}$ Pinus thunbergii Parl.," Zea mays L.,") Alnus glutinosa (L.) Gaertn." and Vicia faba L." We have developed a GC/MS microanalytical method for brassinosteroids as bismethaneboronate derivatives, ${ }^{8)}$ and more recently we have also developed a fluorescence HPLC microanalytical method for them as bis-9-phenanthreneboronate derivatives. ${ }^{9)}$ Further interest in the brassinosteroids contained in pollens prompted us to investigate the presence of the steroids in the pollen of sunflower (Helianthus annuus L.). In this paper, we report the identification of brassinosteroids in this pollen by the HPLC and GC/MS analytical methods.

The sunflower pollen $(2.9 \mathrm{~kg})$ was extracted with methanol and then with ethyl acetatemethanol $(1: 1, v / v)$. The combined extracts were concentrated in vacuo to give an aqueous residue, which was partitioned between chlo-

\footnotetext{
$\dagger$ To whom correspondence should be addressed.
}

roform and water. The organic phase was concentrated and next partitioned between $n$-hexane and $90 \%$ methanol. The aqueous methanol phase was concentrated and further partitioned between chloroform and sat. sodium bicarbonate solution. The chloroform phase showed strong biological activity in a rice lamina inclination test, $\left.{ }^{10}\right)$ which was used to guide the further fractionation. The concentrated chloroform fraction was subjected to chromatography on silica gel, eluting step-wise with increasing concentrations of methanol in chloroform. The eluates with $5 \sim 10 \%$ methanol in chloroform were found to be biologically active (Fig. 1). These fractions were combined, concentrated and further purified by preparative thin-layer chromatography (pTLC), using chloroform methanol $(10: 1, \mathrm{v} / \mathrm{v})$ as the developing solvent. The biological activity appeared in the region of $R f 0.2 \sim 0.4$, which corresponds to the $R f$ values of typical brassinosteroids. These fractions were combined and concentrated to give a partially purified active oil.

An aliquot of this active oil was derivatized with 9-phenanthreneboronic acid. The result- 


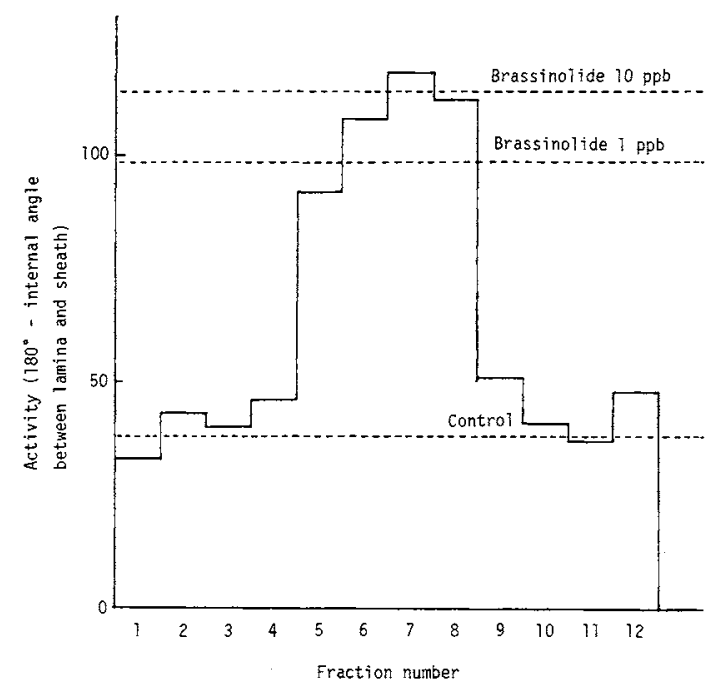

Fig. 1. Distribution of Biological Activity Determined by the Rice Lamina Inclination Test after Silica Gel Adsorption Chromatography of the Extract from Sunflower Pollen.

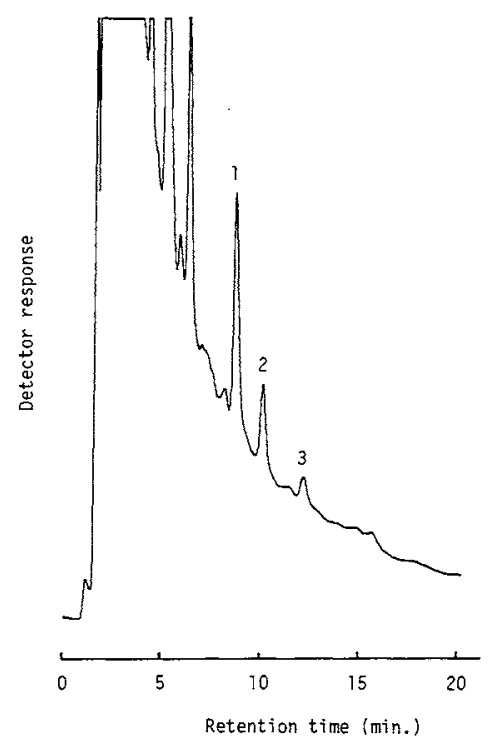

Fig. 2. HPLC Chromatogram of the Bis-9-phenanthreneboronates of Natural Brassinosteroids Obtained from Sunflower Pollen. Peaks: $1=$ brassinolide; $2=$ norcastasterone; 3 = castasterone.

ing boronates were analyzed by reversed-phase HPLC with acetonitrile-water as the mobile phase, and monitored by a fluorometric detector (Ex $305 \mathrm{~nm} / \mathrm{Em} 375 \mathrm{~nm}$ ). ${ }^{9)}$ The chromatogram is presented in Fig. 2. The peaks with retention times of $8.67,10.07$ and 12.15

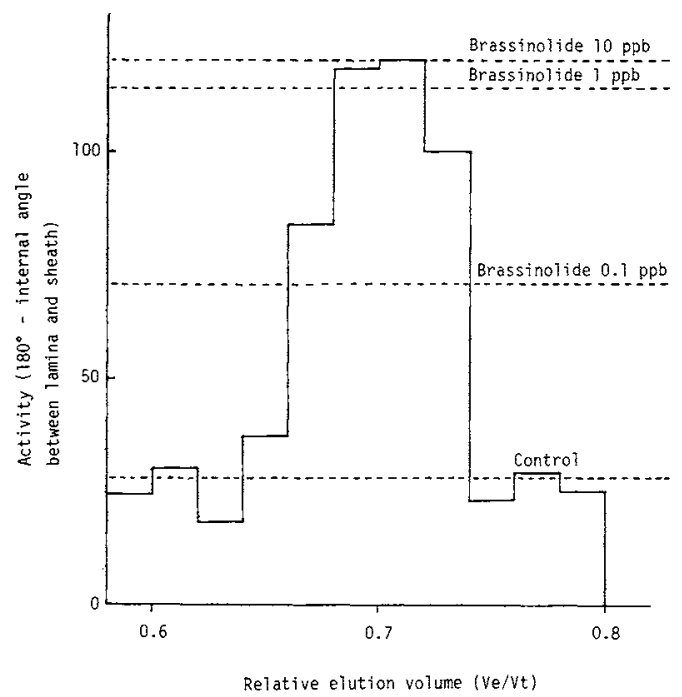

Fig. 3. Distribution of Biological Activity Determined by the Rice Lamina Inclination Test after Sephadex LH-20 Column Chromatography of the Partially Purified Active Oil.

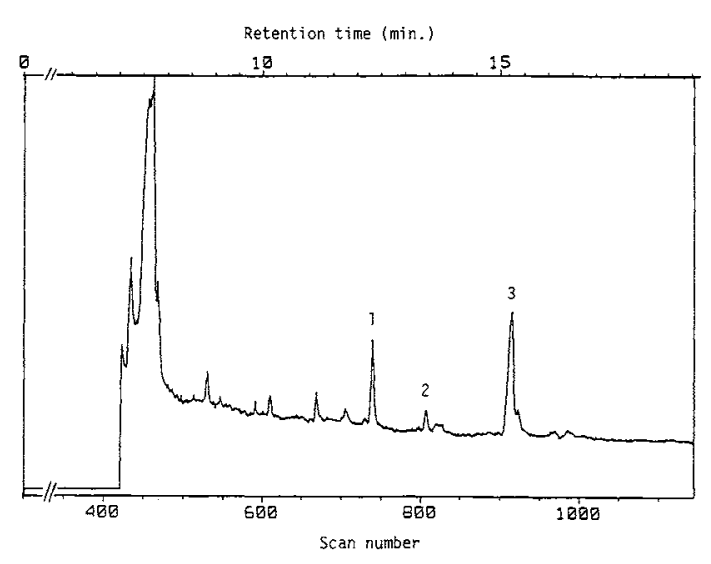

Fig. 4. Total Ion Current Trace in GC/MS of the Methaneboronated Highly Purified Fraction Using a DB1 Fused Silica Capillary Column. Peaks: $1=$ norcastasterone; 2 =castasterone; $3=$ brassinolide.

min were identical with those of the bis-9phenanthreneboronates of authentic brassinolide, norcastasterone (brassinone) and castasterone, respectively. The amounts of these brassinosteroids were calculated by calibrating against authentic samples as 106, 65 and $21 \mu \mathrm{g} / \mathrm{kg}$, respectively.

In order to more precisely identify these brassinosteroids, GC/MS analysis was carried out. The partially purified fraction was further 

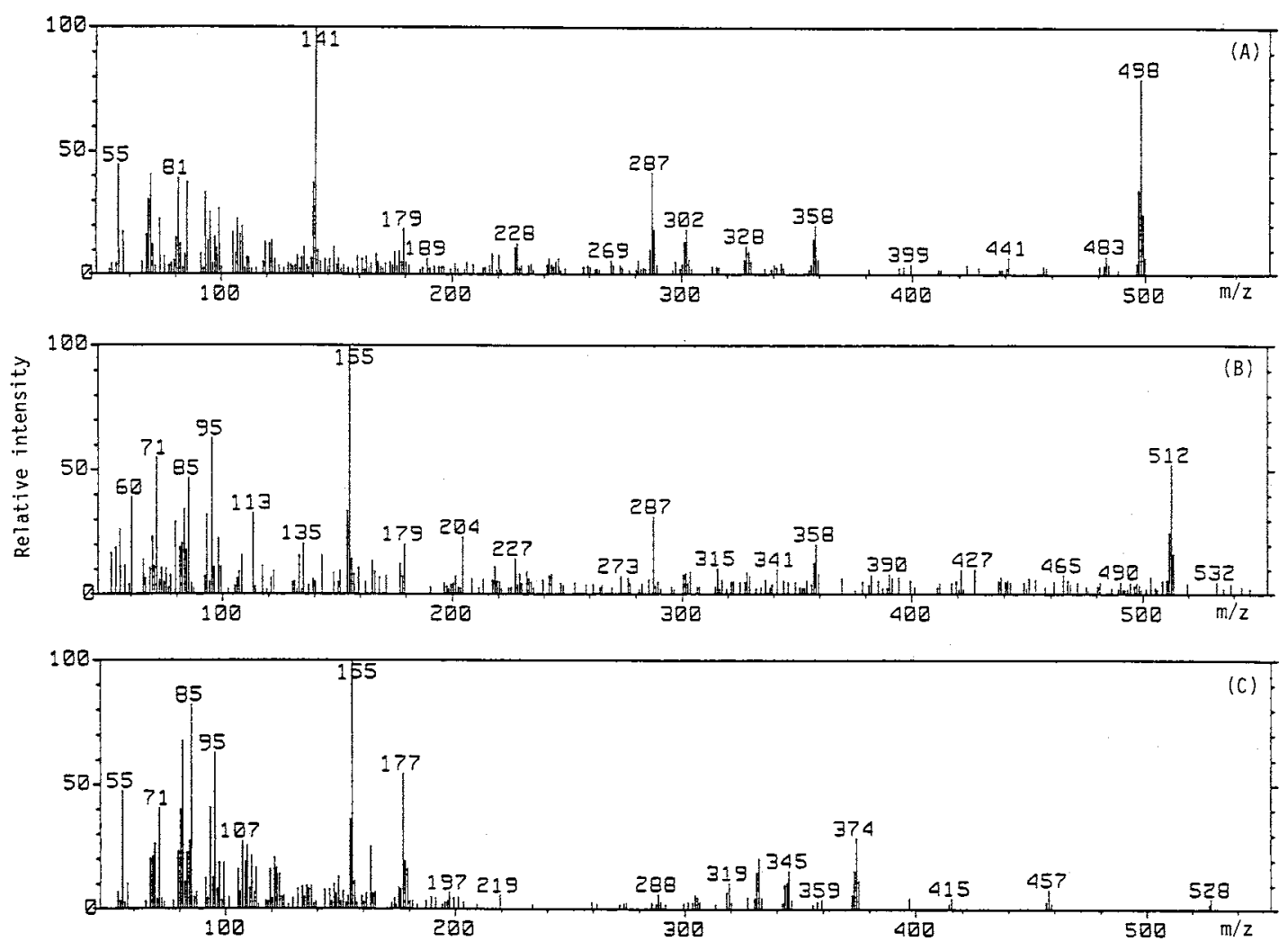

Fig. 5. Electron Impact Mass Spectra of the Bismethaneboronates of Norcastasterone (A), Castasterone (B) and Brassinolide (C) Obtained from the Highly Purified Fraction.

purified by Sephadex LH-20 column chromatography, using methanol-chloroform as the mobile phase. The biological activity was found to be in the elution volume $0.66 \sim 0.74$ $\mathrm{Ve} / \mathrm{Vt}$, corresponding to that of typical brassinosteroids (Fig. 3). These fractions were collected and concentrated to give a highly purified fraction. A small portion of this was converted to bismethaneboronate derivatives ${ }^{83}$ and analyzed by $\mathrm{GC} / \mathrm{EI} / \mathrm{MS}$, using a capillary column. A total ion chromatogram is presented in Fig. 4. The retention times of 12.13, 13.20 and $15.06 \mathrm{~min}$, and mass spectra (Fig. 5) of the peaks were identical with those of the bismethaneboronates of authentic norcastasterone, castasterone and brassinolide, respectively. Thus, the biologically active brassinosteroids in the sunflower pollen were rigorously identified.

In conclusion, we were able to identify brassinolide, castasterone and norcastasterone (brassinone) in the pollen of sunflower by fluorescence HPLC and GC/MS analyses, thereby indicating the usefulness of our fluorescence HPLC microanalytical method for brassinosteroids.

\section{Experimental}

Plant material. The bee-collected pollen of sunflower (Helianthus annuus L.) was obtained from China, and was kindly supplied to us by Nippon Kayaku Co. Ltd. (Tokyo). Identification of the pollen was carried out by a microscopic examination.

Brassinosteroids. Authentic brassinolide, castasterone and norcastasterone (brassione) were synthesized in our laboratory, according to the reported method. ${ }^{11)}$

Bioassay. The rice lamina inclination test was carried out according to the reported method, ${ }^{10)}$ using etiolated seedlings of rice (Oryza sativa L. cv Koshihikari).

Extraction. The sunflower pollen $(2.9 \mathrm{~kg})$ was extracted with $\mathrm{MeOH}$ (151) for a week and then with AcOEt- 
$\mathrm{MeOH}(1: 1, \mathrm{v} / \mathrm{v}, 101)$ for another week. The combined extracts were concentrated below $30^{\circ} \mathrm{C}$ in vacuo to give an aqueous residue, which was partitioned between chloroform $(11 \times 2)$ and water $(11)$. The $\mathrm{CHCl}_{3}$ phase was concentrated and then partitioned between $n$-hexane (21) and $90 \% \mathrm{MeOH}(2 \mathrm{I} \times 2)$. The aqueous $\mathrm{MeOH}$ phase was concentrated and further partitioned between $\mathrm{CHCl}_{3}$ (1 l) and sat. $\mathrm{NaHCO}_{3}$ solution $(300 \mathrm{ml} \times 2)$. The $\mathrm{CHCl}_{3}$ phase was dried over anhydrous $\mathrm{MgSO}_{4}$, filtrated and concentrated to give a biologically active oil $(42.5 \mathrm{~g})$. The hexane phase was concentrated to give an oily material $(108.7 \mathrm{~g})$.

Silica get adsorption chromatography. The active oil $(42.5 \mathrm{~g})$ was charged onto a column $(3.5 \mathrm{~cm}$ i.d. $\times 35 \mathrm{~cm})$ of $\mathrm{SiO}_{2}$ (E. Merck, Kieselgel 60, 70 230 mesh). Elution was carried out step-wise with $\mathrm{CHCl}_{3}(600 \mathrm{ml})$ and then with $\mathrm{CHCl}_{3}-\mathrm{MeOH} \quad(98: 2,600 \mathrm{ml} ; 95: 5,600 \mathrm{ml} ; 90: 10$, $600 \mathrm{ml} ; 85: 15,600 \mathrm{ml} ; 80: 20,600 \mathrm{ml})$. The fractions were collected in $300 \mathrm{ml}$ quantities, and an aliquot ( $2 \mathrm{ml}$ ) of each fraction was subjected to the bioassay. The biological activity appeared in the $5 \sim 10 \% \mathrm{MeOH}$ in $\mathrm{CHCl}_{3}$ eluates (Fig. 1), and these fractions were combined and concentrated in vacuo to give an active oil $(1.57 \mathrm{~g})$.

Preparative thin-layer chromatography. The active oil $(1.57 \mathrm{~g})$ was applied to precoated silica gel plates (E. Merck, Kieselgel $60 \mathrm{~F}_{254}, 20 \times 20 \mathrm{~cm}^{2}, 0.5 \mathrm{~mm}$ thickness), which were developed with $\mathrm{CHCl}_{3}-\mathrm{MeOH}(10: 1, \mathrm{v} / \mathrm{v})$. The silica gel plates were scrapped off into ten bands, each being eluted with $\mathrm{CHCl}_{3}-\mathrm{MeOH}(15: 1, \mathrm{v} / \mathrm{v})$, and the eluates were adjusted to $100 \mathrm{ml}$ each fraction. An aliquot $(0.1 \mathrm{ml})$ of each fraction was subjected to the bioassay. Strong activity appeared in the region of $R f 0.2 \sim 0.4$, and these fractions were combined and concentrated in vacuo to give a partially purified fraction $(210 \mathrm{mg})$, which was analyzed by HPLC.

HPLC analysis. To a small portion $(1.05 \mathrm{mg})$ of the partially purified fraction was added $100 \mu$ l of a solution of 9-phenanthreneboronic acid $(1 \mathrm{mg} / \mathrm{ml})$ in $1 \%(\mathrm{v} / \mathrm{v})$ pyridine $/ \mathrm{CH}_{3} \mathrm{CN}$. The mixture was heated at $70^{\circ} \mathrm{C}$ for $20 \mathrm{~min}$, and after cooling to room temperature, the solution was diluted with $\mathrm{CH}_{3} \mathrm{CN}$ to $1 \mathrm{ml}$. One microliter of the solution was directly injected into the analytical column.

A Shimadzu Model LC-6A chromatograph equipped with a fluorometric detector (RF-530, Ex $305 \mathrm{~nm} / \mathrm{Em}$ $375 \mathrm{~nm}$ ) and a CR-3A data system was employed. An STR ODS-H reversed phase column $(4.0 \mathrm{~mm}$ i.d. $\times 15 \mathrm{~cm}$, Shimadzu Techno Research) was used at $45^{\circ} \mathrm{C}$. Samples were injected into the column using a Rheodyne rotary valve 7125 syringe-loading injector. The mobile phase was a mixture of $\mathrm{CH}_{3} \mathrm{CN}-\mathrm{H}_{2} \mathrm{O}(90: 10, \mathrm{v} / \mathrm{v})$ with a flow rate of $0.8 \mathrm{ml} / \mathrm{min}$.

Sephadex LH-20 column chromatography. The partially purified fraction ( $54 \mathrm{mg}$ ) obtained from p-TLC was charged onto a Sephadex LH-20 column $(26.6 \mathrm{~mm}$ i.d. $\times 90 \mathrm{~cm})$ and eluted with a mixture of $\mathrm{CHCl}_{3}-\mathrm{MeOH}(1: 4, \mathrm{v} / \mathrm{v})$ at a flow rate of $25 \mathrm{ml} / \mathrm{hr}$. Successive $10 \mathrm{ml}$ fractions were collected, and an aliquot $(20 \mu \mathrm{l})$ of each fraction was subjected to the bioassay. The biological activity was detected in the elution volume of $0.66 \sim 0.74 \mathrm{Ve} / \mathrm{Vt}$ (Fig. 3 ), which was combined and concentrated to give a highly purified fraction $(9.0 \mathrm{mg}$ ) for analysis by GC/MS.

GC/MS analysis. Bismethaneboronation was carried out by treating a sample $(0.9 \mathrm{mg})$ with $50 \mu \mathrm{l}$ of a solution of methaneboronic acid in pyridine $(2 \mathrm{mg} / \mathrm{ml})$ at $70^{\circ} \mathrm{C}$ for $30 \mathrm{~min} .{ }^{8}$ One microliter of the solution was injected into the capillary column. The GC/MS analysis was carried out on a JEOL DX-303 gas chromatograph-mass spectrometer under the following conditions: ionization, EI $(70 \mathrm{eV})$; ionization chamber temp., $180^{\circ} \mathrm{C}$; column, DB-1 fused silica capillary $(0.25 \mathrm{~mm} \times 15 \mathrm{~m}, 0.25 \mu \mathrm{m}$ film thickness); column temp., $170^{\circ} \mathrm{C}$ for $2 \mathrm{~min}$, elevated to $275^{\circ} \mathrm{C}$ at $32^{\circ} \mathrm{C} / \mathrm{min}$ and then elevated to $290^{\circ} \mathrm{C}$ at $2^{\circ} \mathrm{C} / \mathrm{min}$; carrier gas, $\mathrm{He}$ at $1.1 \mathrm{~kg} / \mathrm{cm}^{2}$; splitless mode.

\section{References}

1) (a) G. Adam and V. Marquardt, Phytochemistry, 25, 1787 (1986); (b) T. Yokota, Chemical Regulation of Plants, 22, 10 (1987).

2) M. D. Grove, G. F. Spencer, W. K. Rohwedder, N. Mandava, J. F. Worley, J. D. Warthen, Jr, G. L. Stefferns, J. L. Flippen-Anderson and J. C. Cook, Jr., Nature, 281, 216 (1979).

3) J. A. Schneider, K. Yoshihara, K. Nakanishi and N. Kato, Tetrahedron Leti., 24, 3859 (1983).

4) T. Yokota, M. Arima, N. Takahashi, S. Takatsuto, N. Ikekawa and T. Takematsu, Agric. Biol. Chem., 47, 2419 (1983).

5) Y. Suzuki, I. Yamaguchi, T. Yokota and N. Takahashi, Agric. Biol. Chem., 50, 3133 (1986).

6) R. D. Platter, S. L. Taylor and M. D. Grove, J. Natural Products, 49, 540 (1986).

7) N. Ikekawa, F. Nishiyama and Y. Fujimoto, Chem. Pharm. Bull., 36, 405 (1988).

8) (a) S. Takatsuto, B. Ying, M. Morisaki and N Ikekawa, J. Chromatogr., 239, 233 (1982); (b) N. Ikekawa, S. Takatsuto, T. Kitsuwa, H. Saito, T. Morishita and H. Abe, J. Chromatogr., 290, 289 (1984).

9) K. Gamoh, K. Omote, N. Okamoto and S. Takatsuto, J. Chromatogr., 469, 424 (1989).

10) (a) K. Wada, S. Marumo, N. Ikekawa, M. Morisaki and K. Mori, Plant Cell Physiol., 22, 323 (1981); (b) M. Arima, T. Yokota and N. Takahashi, Phytochemistry, 23, 1587 (1984).

11) S. Takatsuto, N. Yazawa, M. Ishiguro, M. Morisaki and N. Ikekawa, J. Chem. Soc., Perkin Trans. 1, 1984, 139. 